\title{
Dew point temperature of wet air stream at variable pressure
}

\author{
Bogusław Ptaszyński ${ }^{1, *}$, Zbigniew Kuczera ${ }^{1}$, Rafat Łuczak $^{1}$ and Piotr Życzkowski ${ }^{1}$ \\ ${ }^{1}$ AGH University of Science and Technology, Faculty of Mining and Geoengineering, \\ Mickiewicza 30 Av. 30-059 Cracow, Poland
}

\begin{abstract}
One of the examples of how atmospheric air could be utilized includes its use as a carrier of mechanical energy transmitted by various devices, e.g. air compressors, constituting parts of various technical systems. In many of them, atmospheric air is subjected to significant changes in static pressure. This research paper specifies the effect of the variable static pressure on the dew point temperature of wet air. This issue was presented both analytically and graphically. The knowledge will allow to effectively identify these areas in which the water vapour contained in the air will be subject to phase changes, unfavourable for humans.
\end{abstract}

\section{Introduction and objective of study}

Streams of gas mixtures are utilized in numerous fields of technology. They are subjected to specific transformations for various purposes and in various devices. If one of the gaseous components that make up the mixture which is undergoing a given process is subject to a phase change, in thermodynamics such a mixture is called the wet gas [5]. The gaseous components that do not change their state of matter are called the dry gas, while the mixture component that can change its physical state is called moisture. In the vast majority of cases, moisture is present in the wet gas in the form of superheated steam. Knowledge of the temperature at which moisture changes its physical state plays a key role in many issues, for example, a stream of exhaust gas of combustion engines, which contains water vapour that can condense in the exhaust system. It is essential to make sure that this phenomenon does not occur in the exhaust manifold. The ventilation uses wet air that, thermodynamically, is the wet gas, in which water is the moisture. In many technical processes, it is required that the water present in the air stream in the form of superheated steam does not change its state of matter to liquid. In industrial ventilation, it is essential that during the flow of wet air through the ducts, condensation does not occur, as it is a source of corrosion or bacteria proliferation in the ducts. In such cases, the knowledge of the dew point temperature of the wet air is necessary in order to be able to thermally insulate the air transporting ducts effectively. The literature provides for various Formulas for the so-called dew point temperature of wet air [1,7]. Such dependencies, however, do not take into account the change in static pressure in the flow pathway of the wet air stream.

\footnotetext{
* Corresponding author: bptaszynski@gmail.com
} 
The purpose of this research paper is to determine the effect of the variability of static pressure on the dew point temperature of the wet air.

\section{Dew point temperature of wet air at constant pressure}

The dew point of the wet air in isobaric cooling processes is presented in thermodynamics using the $p=f(T)$ plots for the water [5] or for the wet air [6]. Figure 1 illustrates a plot of isobaric cooling of the wet air for constant air pressure, at a constant water content in the form of superheated vapour.
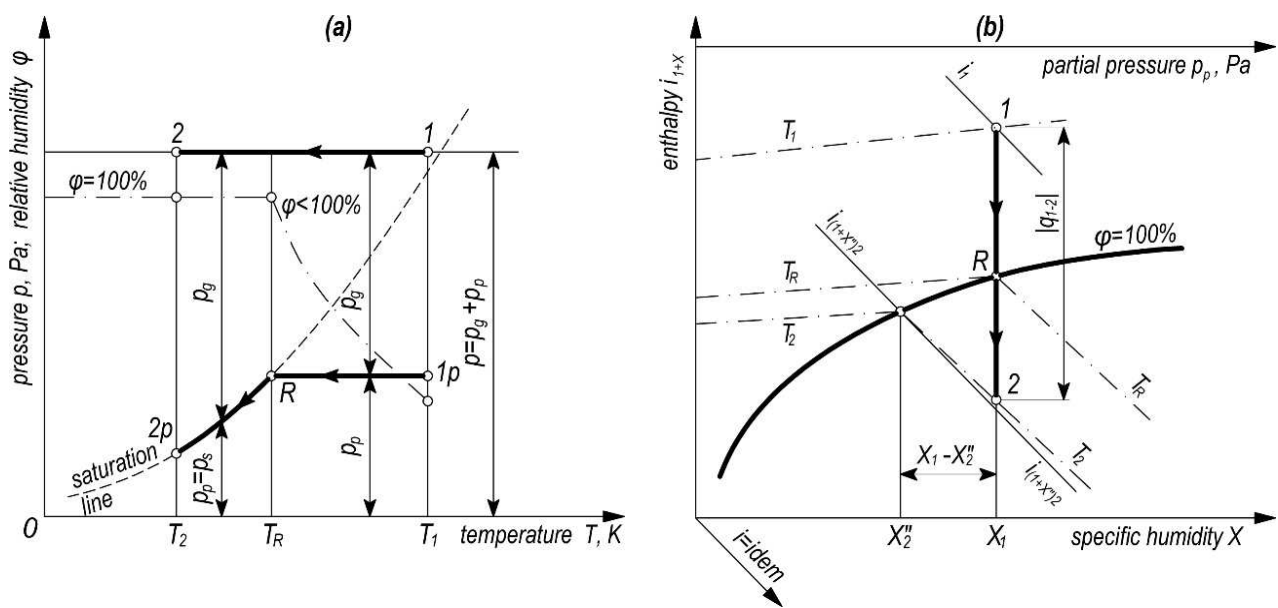

Fig. 1. Isobaric cooling of wet air presented in system a) p,T, b) i,X [6]

Point $1 \mathrm{p}$ in Figure 1a presents the thermodynamic state of steam, determined by the temperature of air and steam $\mathrm{T}$, and the partial pressure of water vapour in the air $\mathrm{p}_{\mathrm{p}}$. The air pressure $\mathrm{p}$ is the sum of the partial pressures of dry air and water vapour. Point 1 represents the thermodynamic state of wet air. The conversion of volumetric cooling of such air at the constant pressure is represented by line 1-2. In this process, the initial state of water (steam) is represented by point $1 \mathrm{p}$, and the final state by point $2 \mathrm{p}$. The dew point is denoted by $\mathrm{R}$ and its coordinate on the abscissa, called the dew point temperature, as $\mathrm{T}_{\mathrm{R}}$. This quantity is more frequently defined in the Celsius scale and denoted as $t_{R}$. The water vapour at the initial point is superheated because the partial pressure of the vapour $p_{p}$ is lower than its saturation pressure read for the point determined from the intersection of the axis perpendicular to the abscissa, passing through point $1 \mathrm{p}$, and the evaporation curve. The dew point $\mathrm{R}$ is the point of intersection of the line illustrating the isobaric cooling of the water vapour from point $1 \mathrm{p}$ and the evaporation curve. If the temperature of the wet air drops, the saturation pressure of the water vapour decreases, while the relative humidity of the air increases. At the dew point $T_{R}$, the initial partial vapour pressure equates to its saturation pressure and the value of the relative humidity reaches $100 \%$. With further cooling of the wet air, the partial pressure of water vapour decreases and is equal to the water vapour saturation pressure. The partial pressure of the dry air for the temperatures $\mathrm{T}<\mathrm{T}_{\mathrm{R}}$ increases accordingly, so that the condition of the cooling process's isobaric was met.

The process of such air cooling is also illustrated in Fig. 1b in the coordinates of the specific enthalpy $i_{1+X}$ and the degree of moisture $X$ [6]. Figure $1 b$ illustrates that the final state of such cooling of wet air is demonstrated in point 2 and it is located in the haze air region. The point of intersection of the $\mathrm{T}_{2}$ isotherm with the $100 \%$ relative humidity curve allows to read the value of the degree of moisturizing the air with the dry saturated steam 
$\mathrm{X}_{2}$ ". On this basis, a generally known definition of the dew point temperature can be explained. It says that it is the highest air temperature at which the vapour contained in the air during its cooling undergoes condensation. However, such an imprecise definition suggests that $t_{R} \geq 0,01^{\circ} \mathrm{C}$. Therefore, Figure 1 should be completed with the information derived from the so-called water phase diagram, i.e. from the p-t diagram for $\mathrm{H}_{2} \mathrm{O}$ [5]. The completion should take into account both the evaporation (condensation) curve and the sublimation (deposition) curve - Figure 2. Based on it, it is possible to say that the dew point $R$ is a point with the temperature $t_{R}$, at which the actual partial vapour pressure is equal to the saturated vapour pressure. The saturated vapour pressure for the temperatures above zero results from the evaporation (condensation) curve, and for the temperatures below zero from the sublimation (deposition) curve. This definition confirms that each wet air has a dew point $\mathrm{R}$ and the corresponding dew point temperature $\mathrm{t}_{\mathrm{R}}$, which can also take negative values. It should also be remembered that for subzero temperatures, in addition to ice, supercooled water may also occur.
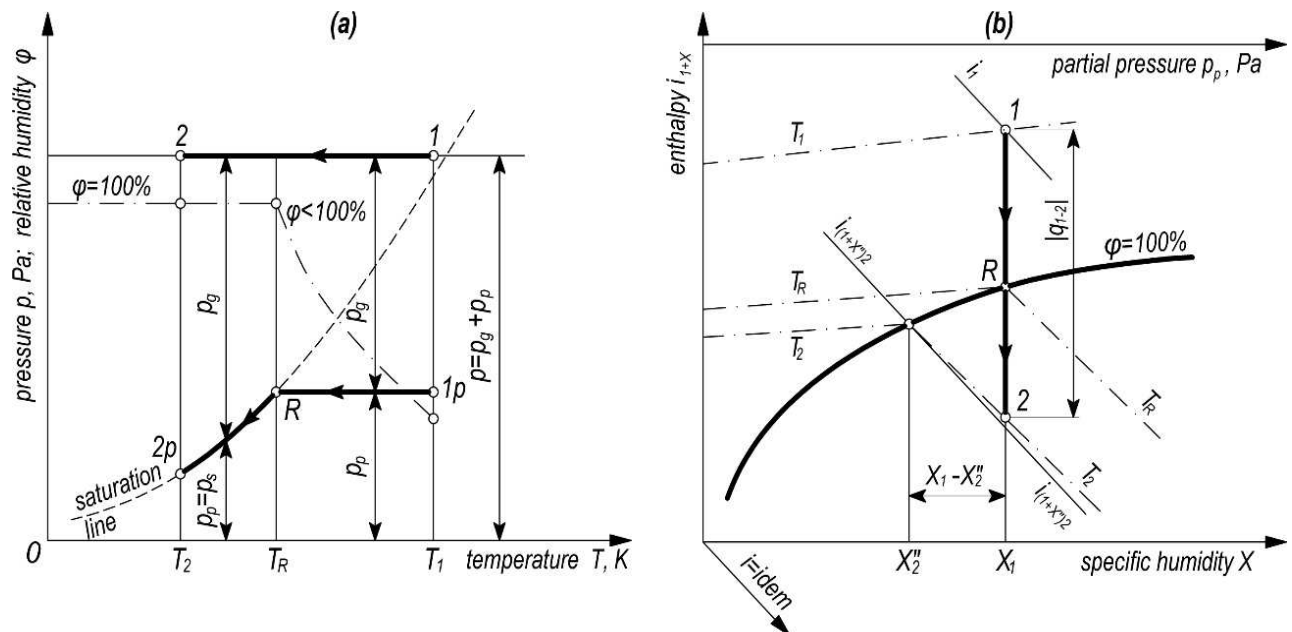

Fig. 2. Isobaric cooling of wet air with evaporation and sublimation curves illustrated in the system a) $\mathrm{p}, \mathrm{T}, \mathrm{b}) \mathrm{i}, \mathrm{X}$

In the further analyzes, empirical Magnus Formula [4] was used for determining the saturated water vapour pressure E:

$$
E=610.6 \cdot 10^{\frac{b(T-273.15)}{T-c}},[P a]
$$

where :

$b \quad-\quad$ constant dependent on air temperature and state of water [-],

$c \quad-\quad$ constant dependent on air temperature and state of water [K],

$T \quad-\quad$ air temperature [K].

For positive and negative values of temperatures of the air which is in contact with supercooled water, the constants in Formula (1) take values: $b=7.5$; $c=35.86 \mathrm{~K}$. On the other hand, for negative values of temperatures of the air which is in contact with ice, the constants are equal to: $b=9.5 ; c=7.66 K$. Using (1), in which $E=p_{p}$ for $T=T_{R}$, Formula for the dew point temperature can be developed as follows: 


$$
p_{p}=610.6 \cdot 10^{\frac{b\left(T_{R}-273.15\right)}{T_{R}-c}},[P a]
$$

Having logarithmized and transformed (2), final Formula is obtained, which defines the temperature of the air dew point:

$$
t_{R}=\frac{(273.15-c)}{b \cdot \ln 10-\ln \frac{p_{p}}{610.6}} \ln ^{\frac{p_{p}}{610.6}},\left[{ }^{\circ} C\right]
$$

where the size $\mathrm{c}$ is dimensionless.

For positive and negative values of temperatures of the air which is in contact with supercooled water, the air dew point can be determined from Formula:

$$
t_{R}=\frac{237.29}{17.26935 \cdot \ln 10-\ln \frac{p_{p}}{610.6}} \ln ^{\frac{p_{p}}{610.6}},\left[{ }^{\circ} C\right]
$$

For negative values of temperatures of the air which is in contact with ice, the air dew point temperature can be determined from Formula:

$$
t_{R_{L}}=\frac{265.49}{21.87456 \cdot \ln 10-\ln \frac{p_{p}}{610.6}} \ln ^{\frac{p_{p}}{610.6}},\left[{ }^{\circ} \mathrm{C}\right]
$$

For wet air with a low value of vapour pressure pp, the dew point values calculated according to (4) and (5) will differ. Examples of values for different vapour pressures are demonstrated in Table 1.

Table 1. Dew point temperature for different values of vapour pressure.

\begin{tabular}{|c|c|c|c|c|c|}
\hline \multirow{2}{*}{} & \multicolumn{5}{|c|}{ Dew point temperature, ${ }^{\circ} \mathrm{C}$} \\
\cline { 2 - 6 } & $\mathrm{p}_{\mathrm{p}}=610.6 \mathrm{~Pa}$ & $\mathrm{p}_{\mathrm{p}}=600 \mathrm{~Pa}$ & $\mathrm{p}_{\mathrm{p}}=500 \mathrm{~Pa}$ & $\mathrm{p}_{\mathrm{p}}=400 \mathrm{~Pa}$ & $\mathrm{p}_{\mathrm{p}}=300 \mathrm{~Pa}$ \\
\hline $\mathrm{t}_{\mathrm{R}}$ acc. to Formula (4) & 0.0 & -0.240 & -2.714 & -5.673 & -9.379 \\
\hline $\mathrm{t}_{\mathrm{R}}$ acc. to Formula (5) & 0.0 & -0.212 & -2.403 & -5.036 & -8.354 \\
\hline
\end{tabular}

Relationships between the temperature values contained in Table 1 are confirmed by the positions of the terminal points $2^{*}$ and $2 * *$ of the air cooling process illustrated in Figures 3 and 4 . It should be noted that, most frequently, for such small pressure values of the water vapour in the air subjected to the process of volumetric cooling, we deal with the formation of rime and snow on solid surfaces or on particles present in the air, after reaching the temperature calculated according to (5). However, in some conditions of the wet air cooling process, excess moisture can be obtained in the form of supercooled water, but such physical state is a highly unstable. 


\section{Dew point temperature of wet air at variable pressure}

In processes of cooling flowing wet air streams, static pressure may be subject to significant changes [3], which may lead to condensation of water vapour in the air stream. The presented Formulas for the dew point temperature (4) and (5) do not take into account the effect of changes in static air pressure. As it was demonstrated in [2], variable pressure induces a shift of curves and coordinate axes on the i-X plot (Mollier plot), describing the thermodynamic parameters of the wet air. The consequences of these changes are presented in Fig. 3.
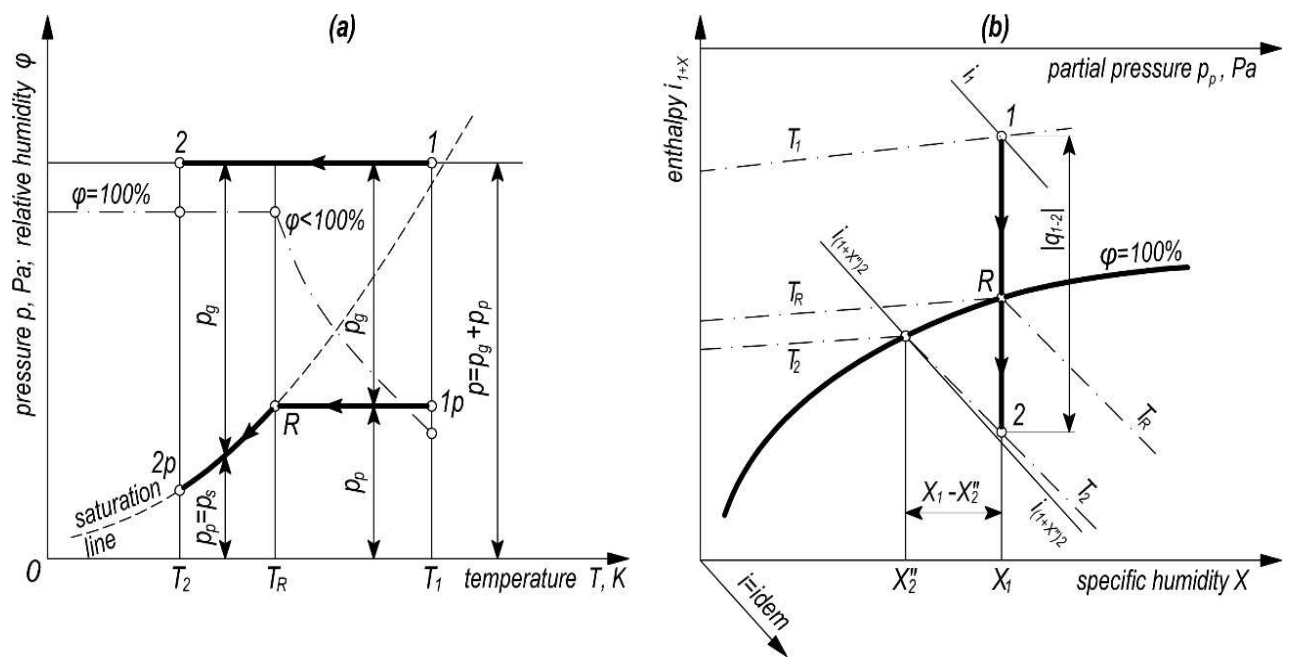

Fig. 3. Isobaric cooling of wet air at variable pressure presented in system a) p,T , b) i,X

It can be noticed that, with the change of pressure, the positions of the evaporation curve and the sublimation curve, connected at the node representing the triple point of water TR, change respectively. With a quick analysis of this plot, a conclusion can be drawn that there are several triple points of water. It is well-known that there is only one triple point of water, defined by its coordinates $\left(\mathrm{T}_{\mathrm{TR}}, \mathrm{p}_{\mathrm{p}(\mathrm{TR})}\right)$. That is why all the TR points marked in Figure 3 have the same coordinates. The partial pressure of the triple point (611.2 Pa) can be read from the horizontal axis placed in the upper part of Figure 3b. Static pressure changes modify the auxiliary axis on the $\mathrm{i}-\mathrm{X}$ plot, showing the values of the partial pressure of water vapour in the air. In Figure 3b, point 1 is marked, representing the thermodynamic state of wet air at the initial pressure and the corresponding dew points $\mathrm{R}$ for different end pressures. The temperature values of its dew points, read from the plot, are different and depend on the variability of pressure. This confirms the existence of the dependence of the dew point temperature on the static pressure of wet air. This dependence is also illustrated in the p-T diagram - Figure 3a. Here are also several TR triple points of water (for different pressures), but in this case, each of these points has the same coordinates. This means that each change in pressure modifies the scale at its ordinate axis, where the partial vapour pressure and the static pressure of the wet air are laid off. Point $1 \mathrm{p}$, marked in Figure 3a, illustrating the thermodynamic state of wet air for the initial pressure and the conversion of its cooling, confirm the existence of the dependence between the dew point value of the wet air and its pressure.

Taking into account the dependence [2]: 


$$
\frac{p_{p}}{p_{p_{1}}}=\frac{p}{p_{1}}
$$

where :

$P \quad-\quad$ static pressure of wet air [Pa],

$p_{I} \quad-\quad$ static pressure of wet air in state $1[\mathrm{~Pa}]$,

$p_{p} \quad-\quad$ partial pressure of water vapour in air for static pressure $p[\mathrm{~Pa}]$,

$p_{p l} \quad-\quad$ partial pressure of water vapour in air for static pressure $p_{1}[\mathrm{~Pa}]$,

Formula for the dew point temperature was developed in the general form:

$$
t_{R}=\frac{(237.15-c)}{b \cdot \ln 10-\left(\ln \frac{p_{p}}{610.6}+\ln \frac{p_{1}}{p}\right)}\left(\ln \frac{\frac{p_{p}}{610.6}}{\ln }+\ln \frac{p_{1}}{p}\right),\left[{ }^{\circ} C\right]
$$

where the size $\mathrm{c}$ is dimensionless.

For positive and negative values of temperatures of the air which is in contact with water (supercooled water in subzero temperatures), the value of the temperature of the air dew point which takes into account the dependence on pressure, takes the following form:

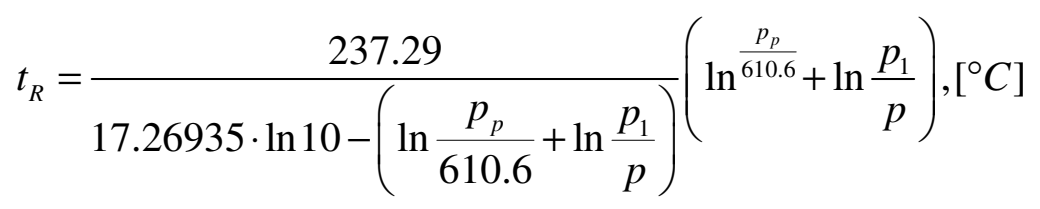

And for negative values of temperatures of the air which is in contact with ice, the value of the temperature of the air dew point which takes into account the dependence on pressure, takes the following form:

$$
t_{R_{L}}=\frac{265.49}{21.87456 \cdot \ln 10-\left(\ln \frac{p_{p}}{610.6}+\ln \frac{p_{1}}{p}\right)}\left(\ln \frac{p_{p}}{610.6}+\ln \frac{p_{1}}{p}\right),\left[{ }^{\circ} C\right]
$$
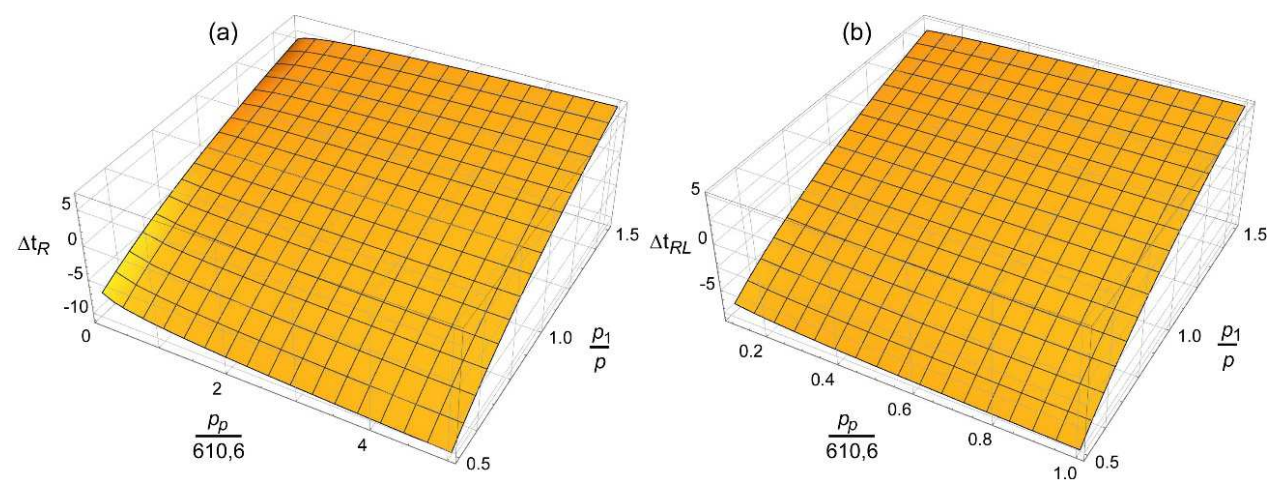

Fig. 4. Difference in temperature of air dew point a) $\Delta t_{R}$ determined from Formulas (8) and (4), b) $\Delta t_{R L}$ determined from Formulas (9) and (5) 
Figure $4 \mathrm{a}$ presents the difference between the temperature of the air dew point $\Delta t_{R}$ determined from (8) which takes into account the variable pressure, and the temperature of the dew point determined from (4) which does not take into account the variable pressure in the range of positive and negative values of air temperatures. Figure 4a illustrates that for the ratio $p_{1} / p=1$, the value $\Delta t_{R}=0$, regardless of the value of the partial pressure of water vapour in the air. If the air pressure $p_{1}$ is lower than the initial pressure $p\left(p_{1} / p<1\right)$, then $\Delta t_{R}<0$, and when the pressure $p_{1}$ is greater than the initial pressure $p$, then $\Delta t_{R}>0$. For the analyzed pressure range, these differences can even reach approximately $-11^{\circ} \mathrm{C}$. On the other hand, Figure $4 \mathrm{~b}$ demonstrates the difference between the temperature of the air dew point $\Delta t_{R L}$ determined from (9) which takes into account the variable pressure, and the temperature of the dew point determined from (5) which does not take into account the variable pressure in the range of negative values of air temperatures. It is also noticeable (as in Fig. 4a) that for the ratio $p_{1} / p=1$, the value $\Delta t_{R L}=0$, regardless of the value of the partial pressure of water vapour in the air. Also, if the air pressure $p_{1}$ is lower than the initial pressure $p\left(\mathrm{p}_{1} / \mathrm{p}<1\right)$, then $\Delta t_{R L}<0$, and when the pressure $p_{1}$ is greater than the initial pressure $p$, then $\Delta t_{R L}>0$. For the analyzed pressure range, these differences can even reach approximately $-7^{\circ} \mathrm{C}$.

\section{Conclusion}

Based on the conducted research, the following conclusions can be formulated:

- The concept of the dew point temperature of the wet air can be explained based on Figure 2, which is an extension of Figure 1 contained in the Literature [6]. Thanks to the proposed changes, it is possible to correctly determine the concept of the dew point temperature for any wet air.

- Formulas for the values of temperature of the air dew point which are the most frequent in Literature, use the dependence between water vapour saturation pressure and water, which for the partial pressures of water vapour in the air which are lower than the pressure of the triple point of water, yields such values of this temperature which can only be obtained in special, very rare cases. However, these Formulas do not include the influence of variable air pressure on the determined value of the dew point temperature.

- Formulas for the dew point temperature of the wet air developed in this paper include the so-called sublimation curve and take into account the influence of variable pressure.

- Differences in the values of the dew point temperature, resulting from variability in air pressure, confirm the usefulness of the developed dependencies.

This research study was supported by the AGH University of Science and Technology statutory research No. 11.11.100.920.

\section{References}

1. Pełech A. Wentylacja i Klimatyzacja. Podstawy, Oficyna Wydawnicza Politechniki Wrocławskiej, Wrocław, (2008)

2. Ptaszyński B. Wykorzystanie wykresu Molliera $\mathrm{w}$ analizie przemian powietrza wilgotnego w wyrobiskach górniczych, Ciepłownictwo Ogrzewnictwo Wentylacja, 10, 47, pp. 389-436, (2016) 
3. Ptaszyński B., Łuczak R., Życzkowski P., Kuczera Z. Thermodynamic processes of the air flowing through a ventilation shaft in underground mines, Archives of Mining Sciences, 1, pp. 149-163, (2018)

4. Roszczynialski W., Wacławik J. Podstawy Aerologii Górniczej, Cz.I, Skrypt AGH Nr 713, Kraków, (1979)

5. Styrylska T. Termodynamika. Podręcznik dla studentów wyższych szkót technicznych, Politechnika Krakowska, Kraków, (2004)

6. Szargut J. Termodynamika Techniczna, Wydawnictwo Politechniki Śląskiej, Gliwice, (2005)

7. Wacławik J. Wentylacja kopalń, Wydawnictwo AGH, Kraków, (2010) 